\title{
Direct synthesis of hydrogen peroxide on palladium catalyst supported on sulfonic acid-functionalized silica
}

\author{
Gema Blanco-Brieva, ${ }^{a}$ M. Pilar de Frutos Escrig, ${ }^{b} J_{0 s e}$ M. Campos-Martin ${ }^{a}$ and Jose L. G. Fierro*a \\ Received (in $X X X, X X X) X$ th $X X X X X X X X X 200 X$, Accepted $X$ th $X X X X X X X X X 200 X$ \\ 5 First published on the web $X$ th $X X X X X X X X X 200 X$ \\ DOI: 10.1039/b000000x
}

The direct synthesis of $\mathrm{H}_{2} \mathrm{O}_{2}$ has been successfully achieved at high-concentration and high selectivity on Pd-loaded sulfonic acid-functionalized silica using non acidic solutions and reaction 10 temperature of $313 \mathrm{~K}$.

Hydrogen peroxide is a clean oxidizing and bleaching agent that is widely used in the environment for water purification/wastewater treatments as a whitening agent and disinfectant, being a basic product in the chemical industry ${ }^{[1]}$.

15 Recently, $\mathrm{H}_{2} \mathrm{O}_{2}$ is drawing growing interest in green chemistry because it acts as direct and environmental benign oxidant in organic synthesis ${ }^{[2]}$ and because its high cost limits the use for the production of bulk organic chemicals. The synthesis of hydrogen peroxide by direct reaction between $\mathrm{H}_{2}$ and $\mathrm{O}_{2}$ is a

20 very attractive alternative to traditional anthraquinone process. Direct synthesis over a Pd-based catalyst was first reported by Henkel and Webel in $1914{ }^{[3]}$ and several studies have been published since then ${ }^{[1]}$. However this process has yet to be put into practice. There are two major drawbacks:

25 (i), the explosive limits of $\mathrm{H}_{2} / \mathrm{O}_{2}$ gas mixtures are very wide ${ }^{[4]}$ and are further widened with increasing pressure; and (ii), another major problem is to achieve good selectivity to $\mathrm{H}_{2} \mathrm{O}_{2}$ yield. To remain outside the explosive region mixtures of $\mathrm{H}_{2}$ and $\mathrm{O}_{2}$ should contain less than about $4 \%$ hydrogen.

30 Acids are often incorporated into the reaction medium to 75 delay or prevent the decomposition of hydrogen peroxide, which indeed takes place in the presence of bases ${ }^{[5]}$. For hydrogen peroxide formation, certain compounds, i.e. some of the halides, have to be added to delay water production, with

35 the subsequent increase in hydrogen peroxide selectivity ${ }^{[5-9]}$. Although halides have good selectivity toward $\mathrm{H}_{2} \mathrm{O}_{2}$ formation, they cause some delay in hydrogen conversion ${ }^{[5,8]}$, suggesting that halide ions are adsorbed on metal centres that indeed participate in the surface reaction between hydrogen

40 and oxygen ${ }^{[7]}$. Among the halides, chlorides and bromides are most often used for this purpose ${ }^{[1,5,7,9]}$. The presence of acid solutions and halide ions in the reaction medium also has a detrimental effect by facilitating the corrosion of reactor material and producing the solution of active metals ${ }^{[11,12]}$.

45 Organic solvents, especially alcohols, are better suited than water because of the greater solubility of $\mathrm{H}_{2}$ and $\mathrm{O}_{2}{ }^{[13]}$. Methanol gives the highest rate of reaction ${ }^{[14,15]}$. Recent studies showed that the functionalization of supports result in an enhancement of hydrogen peroxide yields ${ }^{[16]}$. This 50 observation is related to our earlier studies ${ }^{[17,18]}$ in which we reported a new catalytic system, consisting in the anchoring of Pd (II) ions onto ion-exchange resins functionalized with sulfonic groups. This system produces hydrogen peroxide by direct reaction between $\mathrm{H}_{2}$ and $\mathrm{O}_{2}$ in methanol, and yields 55 high-concentration, non-corrosive $\mathrm{H}_{2} \mathrm{O}_{2}$ solutions with high selectivity ${ }^{[17,18]}$. The high yield attained with these catalysts is related to the interaction of sulfonic groups with palladium moieties. However, resin-based catalysts suffer from a lack of mechanical strength, thermal stability, and low specific area.

60 An alternative support is amorphous silica, which has high specific area and very high mechanical strength, as the silica surface can be properly functionalized with sulfonic acid groups ${ }^{[19]}$ similarly to sulfonic resins. A catalytic system based on this concept has been recently patented ${ }^{[20]}$.

65 Here we report a study of a catalytic system consisting of supported palladium nanoparticles deposited on commercial silica functionalized with sulfonic acid groups for the production of $\mathrm{H}_{2} \mathrm{O}_{2}$ by direct synthesis between $\mathrm{H}_{2}$ and $\mathrm{O}_{2}$ in non-acidic solutions outside the explosive limits of $\mathrm{H}_{2} / \mathrm{O}_{2}$ 70 mixtures. The use of this catalyst yields a high-concentration hydrogen peroxide solution with high selectivity.

In a first step, a sample of functionalized commercial silica (Silycicle Tosic Acid) (10 g) was stirred with $125 \mathrm{~mL}$ of acetone. To this suspension, a palladium (II) acetate (Johnson

75 Matthey) solution in acetone $(50 \mathrm{~mL})$ was dropwise added. The suspension was stirred for $1 \mathrm{~h}$. The remaining solution was filtered off and the solid obtained was washed and airdried at $333 \mathrm{~K}$ for $2 \mathrm{~h}$. Four catalysts with different palladium loadings were prepared according to this procedure (Table 1). 80 In all cases, the amount of Pd incorporated, determined by ICP-AES (Perkin-Elmer Optima 3300 DV) to the silica was similar to the nominal one.

Table 1 Palladium concentration and BE of Pd core level spectra

\begin{tabular}{lll}
\multicolumn{1}{c}{ Sample } & \multicolumn{1}{c}{ Pd (wt\%) } & \multicolumn{1}{c}{ BE Pd 3d $\mathrm{d}_{5 / 2}(\mathrm{eV})$} \\
\hline PdSiTA-1 & 1.92 & $338.1(89), 336.2(11)$ \\
PdSiTA-2 & 0.97 & $338.1(90), 336.2(10)$ \\
PdSiTA-3 & 0.50 & $338.1(91), 336.2(9)$ \\
PdSiTA-4 & 0.26 & $338.1(90) 336.2(10)$ \\
\hline
\end{tabular}

Number in parenthesis are peak proportions

The XRD profiles (X'Pert Pro PANalytical) of the samples showed only a broad peak due to silica substrate, but no 90 diffraction lines of palladium species were observed. This fact 
indicates that the size of palladium particles is very small or non-crystalline. Samples were analyzed by TEM (JEOL 2100Fx), being difficult to measure in transmission mode, mainly due to the small particle size. It was therefore

5 necessary to analyze in STEM mode, which magnifies the contrast between support and the palladium species (see Figure 1 and supporting information). All samples showed a homogeneous distribution of Pd particles with a size around 3$4 \mathrm{~nm}$.

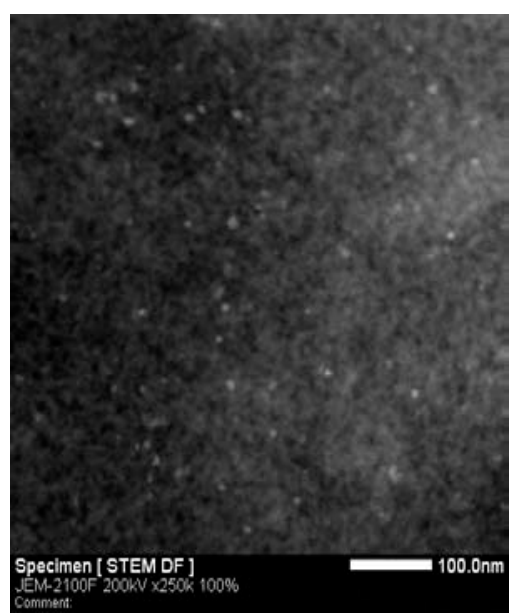

10

Figure 1 STEM image of PdSiTA-1 sample.

Catalysts were tested in direct synthesis of hydrogen peroxide. In a typical run, $1.6 \mathrm{~g}$ of the catalyst was put inside an autoclave with $150 \mathrm{~g}$ of methanol and $\mathrm{HBr}$ as promoter. The

15 reactor was pressured with nitrogen to $9.5 \mathrm{MPa}$. The mixture was heated to $313 \mathrm{~K}$. Then, the reaction gas mixture was feed $\left(\mathrm{H}_{2}: \mathrm{O}_{2}: \mathrm{N}_{2}=3.6: 46.4: 50\right)$ with a total flow of $2500 \mathrm{~mL}(\mathrm{~N})$ $\mathrm{min}^{-1}$, and then the suspension was stirred (1500 rpm) to initiate the reaction. The reproducibility of the results is very

20 high as demonstrated by replica experiments in which differences in product concentration smaller than 0.2 wt \% were observed (see error bar in Figure 2) Two blank 60 experiments have been performed using the support and palladium (II) acetate. In both cases no hydrogen peroxide

25 formation was detected.

There is a strong influence in the yield to hydrogen peroxide and the promoter concentration (bromide) ${ }^{[5-8]}$. For this reason, different $\mathrm{HBr} / \mathrm{Pd}$ weight ratios have been studied. The concentration studied was around the optimum one found

30 previously for catalysts based on sulfonic resins ${ }^{[17,18]}$. The concentration of hydrogen peroxide clearly increases linearly in all experiments (Figure 2), but the final $\mathrm{H}_{2} \mathrm{O}_{2}$ concentration changes with the $\mathrm{HBr} / \mathrm{Pd}$ ratio. The final hydrogen peroxide concentration increased with the $\mathrm{HBr} / \mathrm{Pd}$ ratio peaking at

35 around 0.160 , then decreasing slightly at a higher $\mathrm{HBr} / \mathrm{Pd}$ value. Selectivity to $\mathrm{H}_{2} \mathrm{O}_{2}$ decreased with the time of reaction (concentration of $\mathrm{H}_{2} \mathrm{O}_{2}$ ) in all cases. But this drop became more evident when the $\mathrm{HBr} / \mathrm{Pd}$ ratio is lower than 0.150 (Figure 2). Consequently, the maximum yield to hydrogen 40 peroxide found for the $\mathrm{HBr} / \mathrm{Pd}=0.160$ is due to a high selectivity to $\mathrm{H}_{2} \mathrm{O}_{2}$ and hydrogen conversion. In all cases the hydrogen conversion was above $90 \%$. This optimum value corresponds to $24 \mathrm{ppm}$ of $\mathrm{HBr}$, which implies an almost neutral solution.
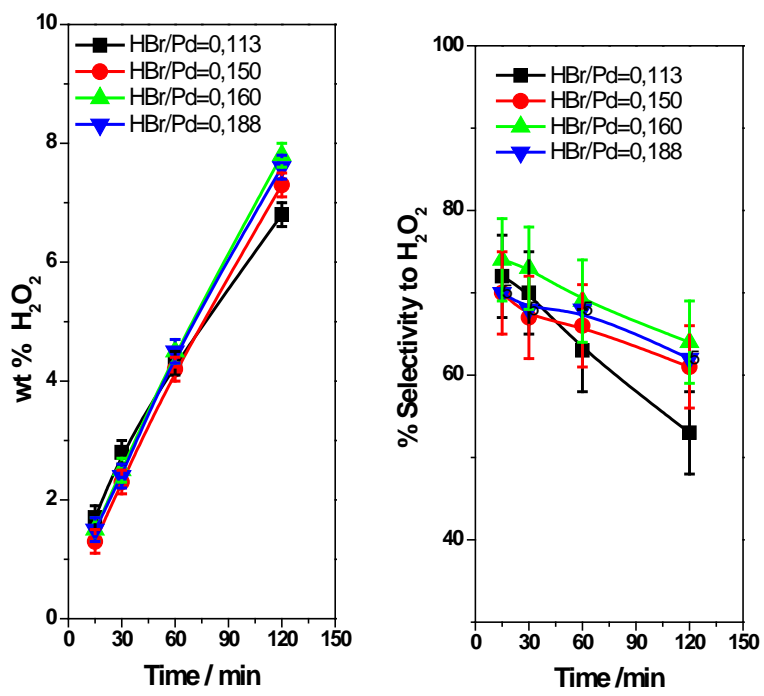

Figure 2 Influence of the weight ratio $\mathrm{HBr} / \mathrm{Pd}$ in the PdSiTA-2 catalyst on its performance in the $\mathrm{H}_{2} \mathrm{O}_{2}$ concentration and selectivity profile versus time along the direct reaction of hydrogen and oxygen at $313 \mathrm{~K}$.

50 The effect of palladium loading in the catalyst was studied. Pdloadings ranged from $1.92 \mathrm{wt} \%$, corresponding to the exchange capacity of the support, to $0.26 \mathrm{wt} \%$, about 8 times lower. These catalysts were analyzed by XPS. The photoelectron spectra of the Pd 3d core-levels showed the characteristic spin-orbit splitting of

55 Pd 3d levels. Each component of the Pd 3d doublet appeared broad and asymmetric, suggesting that two palladium species are present. The peaks were fitted by a non-linear least square fitting routine using a properly weighted sum of Lorentzian and Gaussian component curves after background subtraction with 60 Shirley line. By applying peak fitting procedures, two palladium species were identified (Figure 3, Table 1).

For the most intense $\mathrm{Pd} 3 \mathrm{~d}_{5 / 2}$ level, one of these components appeared at $336.5 \mathrm{eV}$, which is usually assigned to $\mathrm{PdO}$ clusters, and the second one at $338.2 \mathrm{eV}$, corresponding to $\mathrm{Pd}$

65 (II) ions interacting with the $-\mathrm{SO}_{3} \mathrm{H}$ anchored to the silica substrate. All catalysts exhibited a higher amount of $\mathrm{Pd}(\mathrm{II})$ species interacting with $-\mathrm{SO}_{3} \mathrm{H}$ groups and a lower quantity of PdO species, which affords a high selectivity and conversion of $\mathrm{H}_{2} \mathrm{O}_{2}$ in liquid phase ${ }^{[17,18]}$. No significant differences were 70 observed in the proportion of palladium species.

These catalysts were used in the direct synthesis of hydrogen peroxide, using the same amount of palladium. This was achieved by adjusting the weight of catalyst. The performance in reaction was practically identical for all catalysts (Figure 754 ). For the sake of simplicity, only two curves are shown. The concentration of $\mathrm{H}_{2} \mathrm{O}_{2}$ and selectivity to hydrogen peroxide profiles are very similar. This observation suggests that the active species are identical in all catalysts and proves that 
selectivity and activity data are in agreement with the nature of palladium species ${ }^{[17,18]}$ as revealed by XPS.

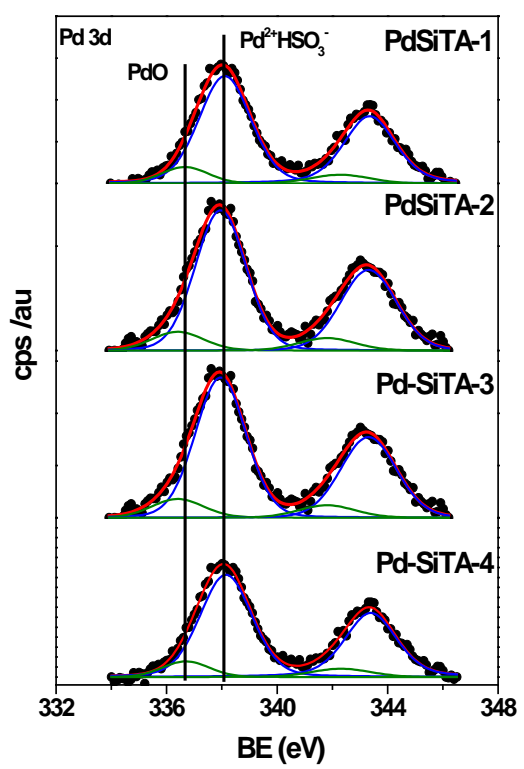

Figure 3 Pd3d core-level spectra of prepared samples.
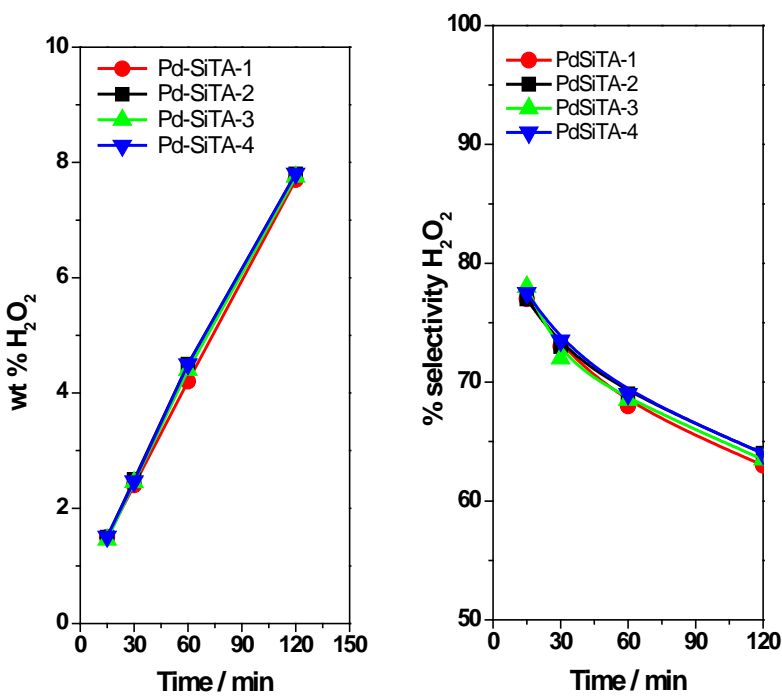

5

Figure 4 Dependence between $\mathrm{H}_{2} \mathrm{O}_{2}$ concentration/selectivity and reaction time for catalysts with different palladium loading.

In general, reaction data are difficult to compare with those

10 published in open literature because reaction conditions are different. In the present work, we have used a reaction temperature of $313 \mathrm{~K}$, which is much more attractive from an industrial perspective and differs substantially from that used in most of the published works (273-278 K). The higher

15 temperature used in this work has a twofold effect: (i), a high reaction temperature determines a high reaction rate, and therefore much higher hydrogen peroxide concentrations are obtained for shorter reaction times (7-8 wt\% in this work), which contrasts with the much lower concentrations usually 20 reported in the literature; and (ii), the reaction temperature of $313 \mathrm{~K}$ selected in this work is closer to industrial application because the reaction $\mathrm{H}_{2}+\mathrm{O}_{2} \rightarrow \mathrm{H}_{2} \mathrm{O}_{2}$ is highly exothermic and hence the heat released must be removed, this being easier at $313 \mathrm{~K}$ than at $278 \mathrm{~K}$.

25 From Figure 4 it is clear that the values of $\mathrm{H}_{2} \mathrm{O}_{2}$ selectivity depend strongly on hydrogen peroxide concentration levels. In order to compare the performance of our catalysts with that reported in the literature, $\mathrm{H}_{2} \mathrm{O}_{2}$ selectivity values in Table 2 have been extrapolated to the $\mathrm{H}_{2} \mathrm{O}_{2}$ concentration region

30 below 1 wt\%. This simple procedure allowed us to make a reliable comparison of $\mathrm{H}_{2} \mathrm{O}_{2}$ productivity. The data collected in Table 2 allow us to conclude that this family of catalysts supported on $\mathrm{HSO}_{3}$-functionalized silica, and specifically PdSiTA-1, produce high $\mathrm{H}_{2} \mathrm{O}_{2}$ yields with a high selectivity to $35 \mathrm{H}_{2} \mathrm{O}_{2}$, and thus they are promising for industrial exploitation.

Finally, the reuse of the catalysts was studied for PdSiTA-1 sample. No changes in the catalytic activity were observed after 15 operation cycles. Reactor effluent was analysed and no measurable amount of leached palladium was observed.

40 Table 2 Selectivity and yield towards $\mathrm{H}_{2} \mathrm{O}_{2}$ for different catalysts

\begin{tabular}{|c|c|c|}
\hline Sample & $\begin{array}{c}\text { Selectivity to } \mathrm{H}_{2} \mathrm{O}_{2} \text { at } \\
0.5 \text { wt } \% \mathrm{H}_{2} \mathrm{O}_{2}\end{array}$ & $\begin{array}{c}\mathrm{H}_{2} \mathrm{O}_{2} \text { yield }^{[\mathrm{a}]} \\
\left(\mathrm{mol} \mathrm{kg}_{\text {cat }}{ }^{-1} \mathrm{~h}^{-1}\right)\end{array}$ \\
\hline PdSiTA-1 & 83 & 335 \\
\hline PdSiTA-2 & 84 & 165 \\
\hline $2.5 \% P d-2.5 \% A u /$ Carbon $^{[\mathrm{b}]}$ & 98 & 175 \\
\hline
\end{tabular}

In short, the new catalyst system of supported palladium nanoparticles deposited on $\mathrm{HSO}_{3}$-functionalized commercial 45 silica used here produces hydrogen peroxide with a high yield (335 mol kg ${ }^{-1} \cdot \mathrm{h}^{-1}$ ) by feeding a non-flammable $\mathrm{H}_{2} / \mathrm{O}_{2}$ mixture into a non-acidic catalyst-methanol suspension at $313 \mathrm{~K}$. The advantages provided by this approach offer the possibility of industrial application.

50 The authors acknowledge financial support from Repsol-YPF (Spain) and the Spanish Ministry of Science and Innovation under projects PSE-310200-2006-2 and FIT-320100-2006-88. GBB acknowledges a fellowship granted by Repsol-YPF.

\section{Notes and references}

$55^{a}$ Sustaninables Energy and Chemistry Group (EQS). Instituto de Catálisis y Petroleoquímica, CSIC, Marie Curie 2, Cantoblanco, 28049 Madrid, Spain; http://www.icp.csic.es/eac/; Fax: +34915854760; Email:jlgfierro@icp.csic.es

${ }^{b}$ Centro de Tecnología Repsol, A-5, Km. 18, 28931 Móstoles, Madrid, 60 Spain

† Electronic Supplementary Information (ESI) available: STEM micrographs. See DOI: 10.1039/b000000x/

1 G. Blanco-Brieva, J. M. Campos-Martin and J. L. G. Fierro, Angew. Chem. Int. Ed., 2006, 45, 6962; and references therein.

2 G. Goor, W. Kunkel and O. Weiberg, in Ullmann's Encyclopedia of Industrial Chemistry, Vol. A13, (Eds.: B. Elvers, S. Hawkins, M. Ravenscroft, G. Schulz), VCH, Weinheim, 1989, pp. 443-466.

3 H. Henkel and W. Weber, US110875, 1914 
4 L. W. Gosser (E. I. Du Pont de Nemours and Company), EP132294, 1985 [Chem. Abs., 1985, 102, 134404].

$5 \quad$ R. Burch and P. R. Ellis, Appl. Catal. B: Env., 2003, 42(2), 203.

6 V. R. Choudhary and P. Jana, Appl. Catal. A: Gen., 2007, 329, 79.

57 C. Samanta and V. R. Choudhary, J. Catal., 2007, 330, 31.

8 S. Chinta and J. H. Lunsford, J. Catal., 2004, 225, 249.

9 T. Moreno, J. Garcia-Serna and M. J. Cocero, Green Chem., 2010, 12, 282

10 C. Samanta and V. R. Choudhary, Appl. Catal. A: Gen., 2007, 326, 32

11 D. P. Dissanayake and J. H. Lunsford, J. Catal., 2002, 206, 173.

12 D. P. Dissanayake and J. H. Lunsford, J. Catal., 2003, 214, 113.

13 a) N. C. Patel, V. Abovsky and S. Watanasiri, Fluid Phase Equilibria, 2001, 185, 397; b)R. Fernandez-Prinia, J. L. Alvarez and

15 A. H. Harvey, J. Phys. Chem. Ref. Data, 2003, 32(2), 903; c) S. Fan, J. Yi ,L. Wang and Z. Mi, React. Kinet. Catal. Lett., 2007, 92, 179.

14 J. K. Edwards, B. E. Solsona, P. Landon, A. F. Carley, A. Herzing, C. J. Kiely and G. J. Hutchings, J. Catal., 2005, 236, 69.

15 G. Centi, S. Perathoner, Catal. Today, 2009, 143(1-2), 145.

2016 J. K. Edwards, B. Solsona, E. Ntainjua N., A. F. Carley, A. A. Herzing, C. J. Kiely, G. J. Hutchings, Science, 2009, 323, 1037

17 G. Blanco-Brieva, E. Cano-Serrano, J. M. Campos-Martin and J. L. G. Fierro, Chem Commun., 2004, 1184.

18 G. Blanco-Brieva, M. C. Capel-Sanchez, M. P. de Frutos, J. M. Campos-Martin and J. L. G. Fierro, Ind. Eng. Chem. Res., 2008, 47, 8013.

19 a) E. Cano-Serrano, J. M. Campos-Martin, and J. L. G. Fierro, Chem.Commun., 2003, 246; b) E. Cano-Serrano, G, Blanco-Brieva, J. M. Campos-Martin and J. L. G. Fierro Langmuir, 2003, 19, 7621.

3020 E. Cano-Serrano, G, Blanco-Brieva, J. M. Campos-Martin and J. L. G. Fierro (Repsol Química S.A.), EP2000205A1, 2008. 
Supporting information

\section{Direct synthesis of hydrogen peroxide on palladium catalyst supported on sulfonic acid-functionalized silica}

Gema Blanco-Brieva ${ }^{1}$, M. Pilar de Frutos ${ }^{2}$, Jose M. Campos-

$$
\text { Martin }^{1} \text {, Jose L. G. Fierro }{ }^{1}
$$

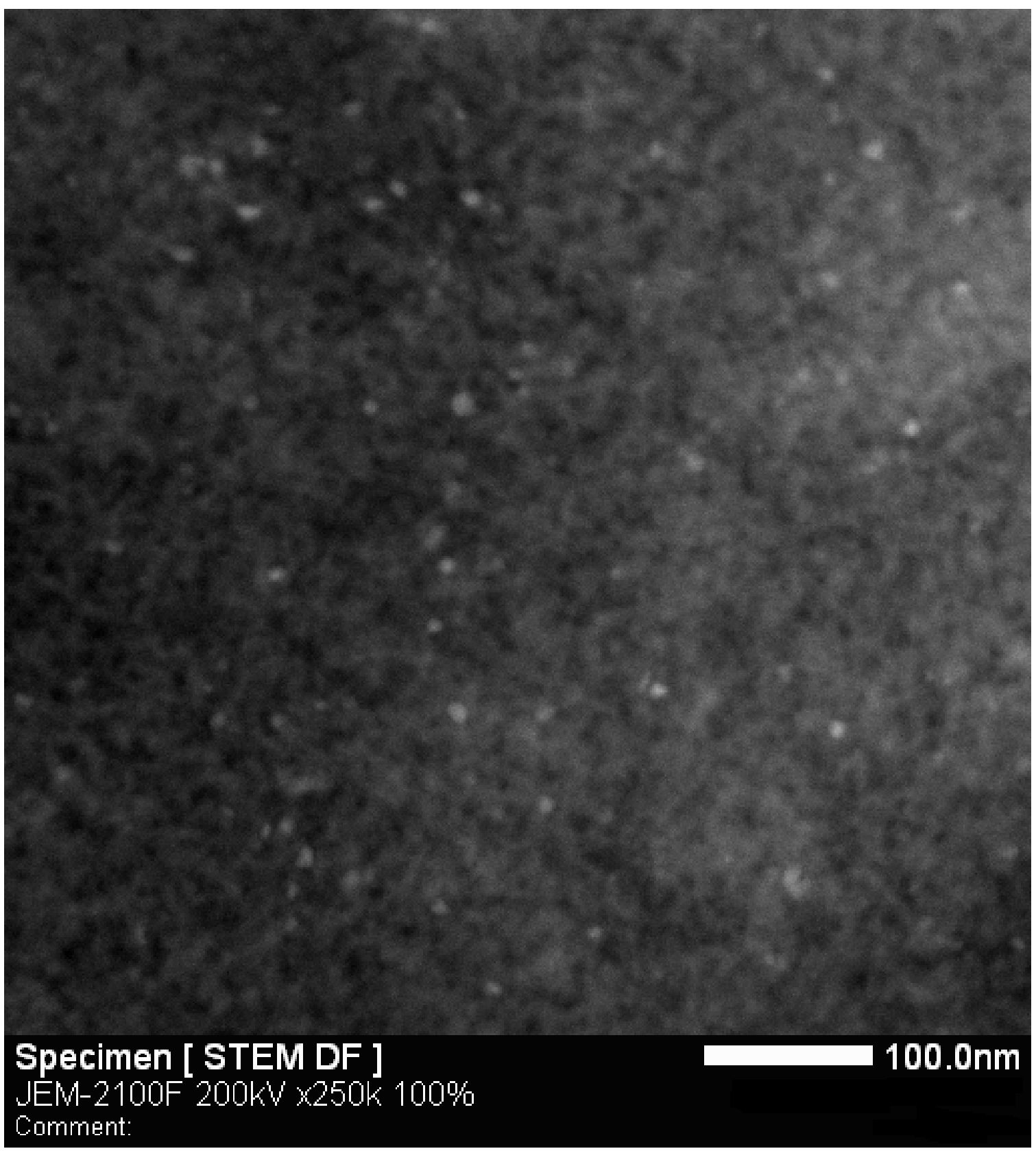

Figure 1S STEM image of PdSiCo-1 sample. 


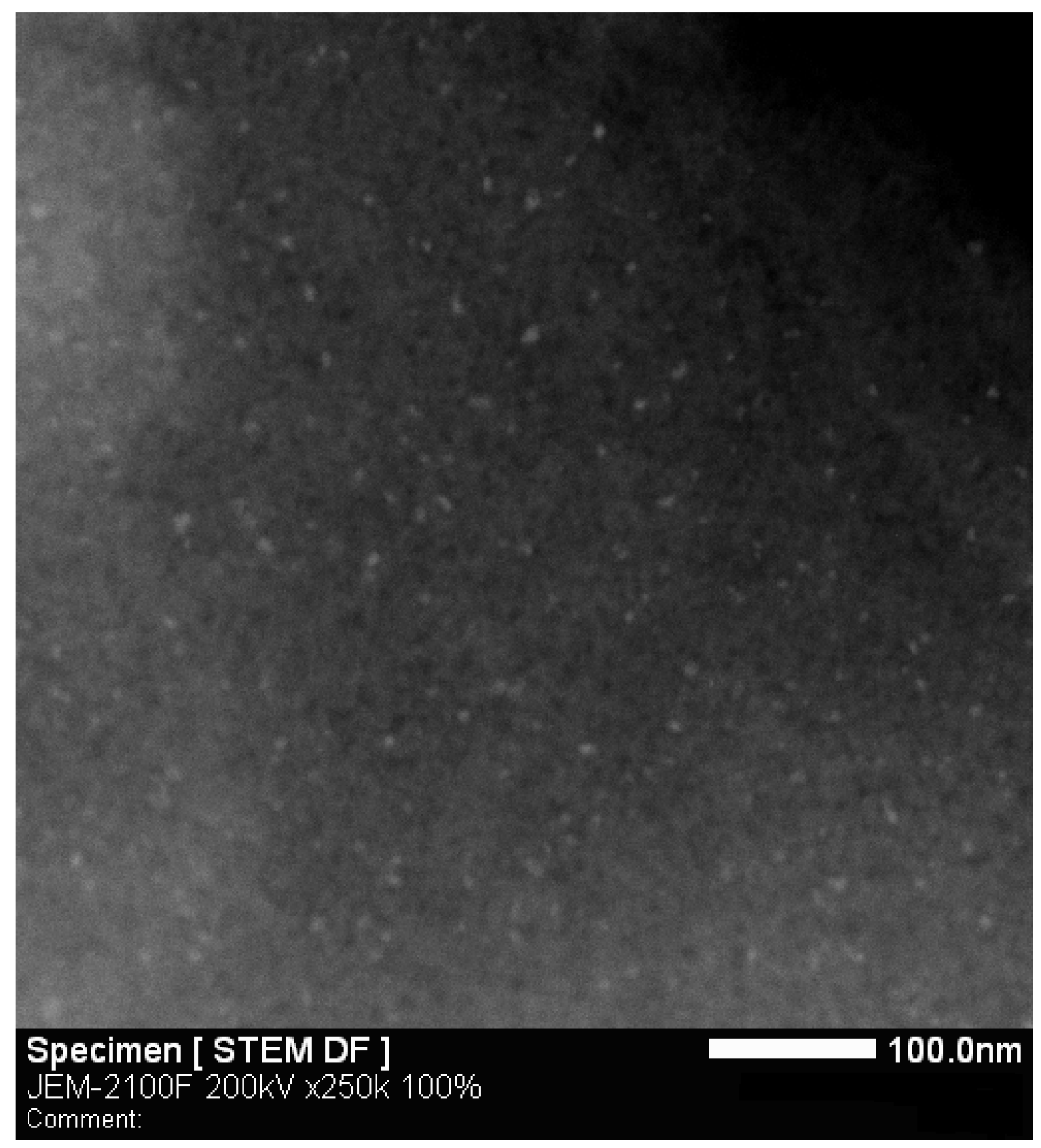

Figure 2S STEM image of PdSiCo-2 sample. 


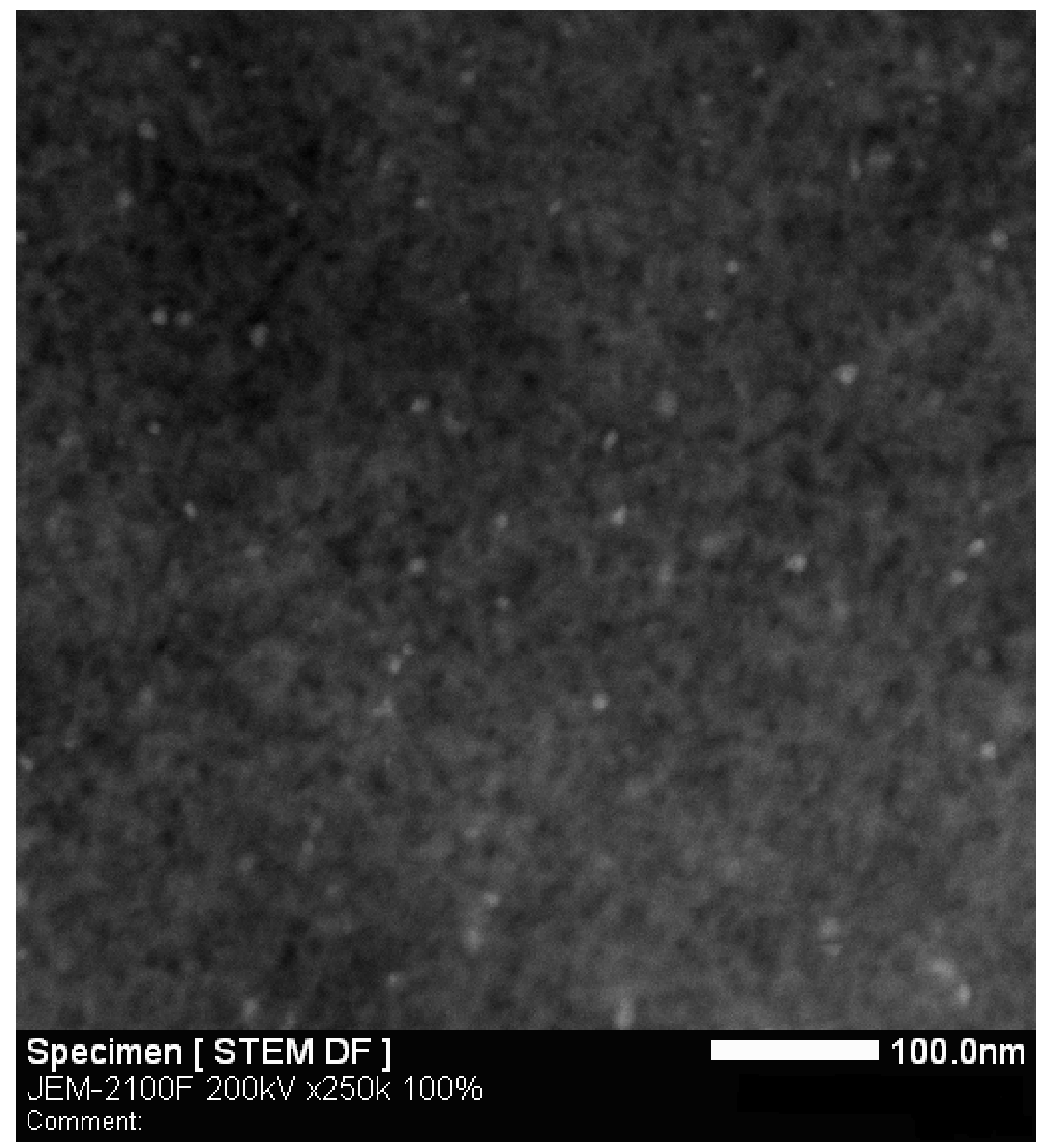

Figure 35 STEM image of PdSiCo-3 sample. 


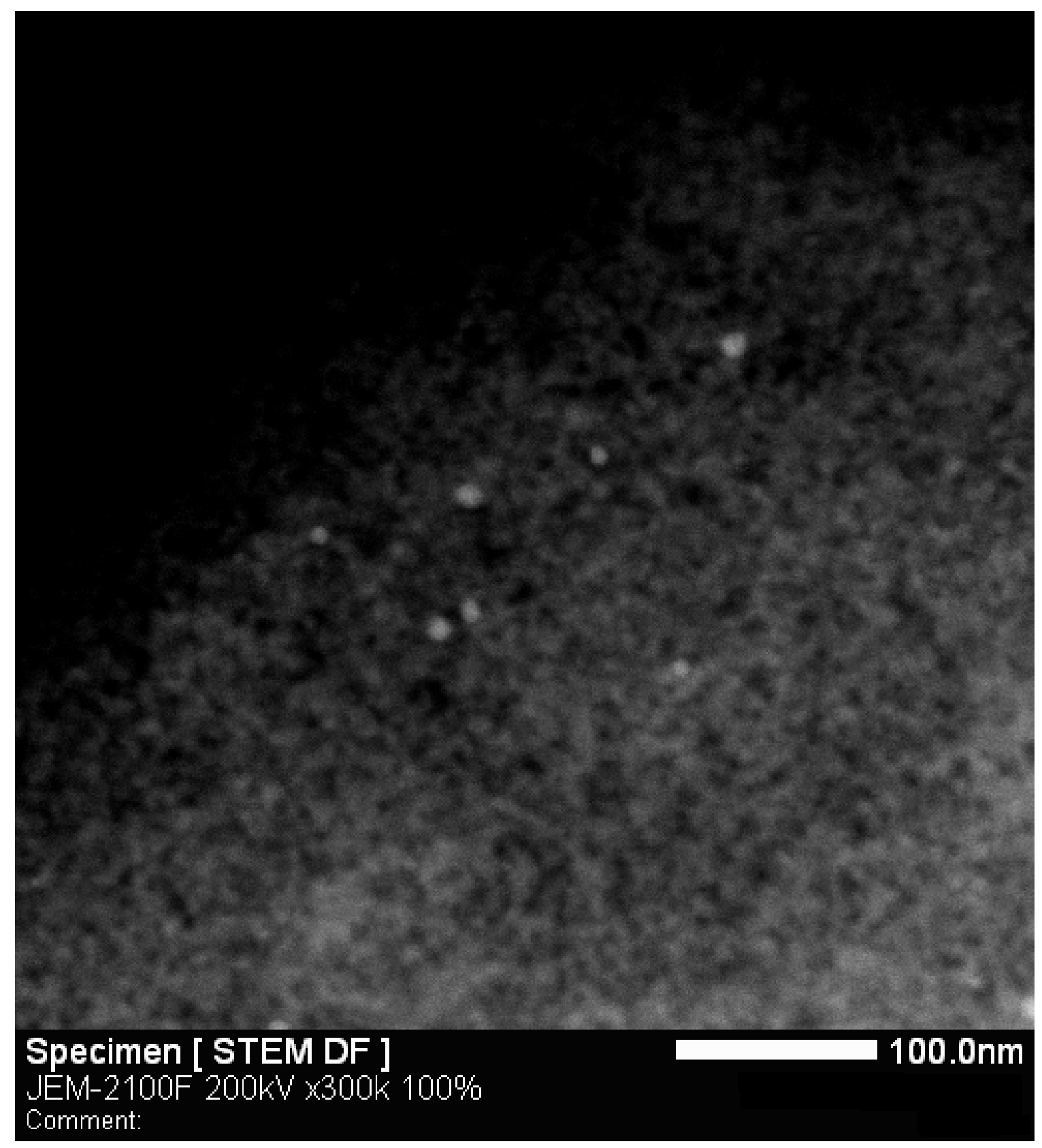

Figure 4S STEM image of PdSiCo-4 sample. 